\title{
Manipulative Signals in Family Conflict? On the Function of Maternal Yolk Hormones in Birds
}

\author{
Wendt Müller, ${ }^{1, *} \mathrm{C}($ Kate $)$. M. Lessells, ${ }^{2, \uparrow}$ Peter Korsten, ${ }^{3, \ddagger}$ and Nikolaus von Engelhardt ${ }^{4, \$}$
}

1. Department of Biology-Ethology, University of Antwerp,

Universiteitsplein 1, 2610 Antwerp (Wilrijk), Belgium;

2. Netherlands Institute of Ecology (NIOO-KNAW), P.O. Box 40, 6666 ZG Heteren, The Netherlands;

3. Animal Ecology Group, University of Groningen, P.O. Box 14, 9750 AA Haren, The Netherlands;

4. Behavioural Biology Research Group, University of Groningen, P.O. Box 14, 9750 AA Haren, The Netherlands

Submitted June 7, 2006; Accepted November 16, 2006;

Electronically published January 25, 2007

AвSTRACT: Maternal hormones in the yolk of birds' eggs have been a focus of attention in behavioral and evolutionary ecology stimulated by the pioneering work of Hubert Schwabl. Since then, knowledge of both the factors that influence maternal deposition patterns and their consequences for offspring development has accumulated rapidly. To date, the field has been dominated by the idea that mothers use yolk hormones to adaptively adjust offspring development, a view that assigns control over hormone deposition and its effects on the offspring to the mother. This neglects the possibility that the evolutionary interests of the mother and offspring differ. When there is such parent-offspring conflict, the offspring are selected to respond to the hormones in a way that is adaptive for themselves rather than for the mother. Moreover, sexual conflict between the parents over parental investment may shape the evolution of yolk hormone deposition: females may manipulate the male's contribution to parental care through the effect of yolk hormones on offspring begging, competitiveness, and developmental rate. We therefore suggest that for a full understanding of the evolution of hormone-mediated maternal effects, it is essential to study both fitness consequences and physiological mechanisms and constraints from the perspective of all family members.

Keywords: testosterone, parent-offspring conflict, sexual conflict, maternal effects, parental care.

\footnotetext{
* Corresponding author; e-mail: wendt.muller@ua.ac.be.

† E-mail: k.lessells@nioo.knaw.nl.

¥ E-mail: p.korsten@rug.nl.

${ }^{\S}$ E-mail: nvengelhardt@gmx.de.
}

Am. Nat. 2007. Vol. 169, pp. E84-E96. (C) 2007 by The University of Chicago. 0003-0147/2007/16904-41887\$15.00. All rights reserved.
Female birds transfer not only nutrients to the eggs they produce but also other substances such as antibodies, RNA, and hormones, all of which are thought to be important for offspring development (Price 1998). They represent examples of so-called maternal effects-where offspring phenotype is influenced by the maternal phenotype-and are thought to have evolved because they translate the environmental conditions experienced by the mother and her partly heritable physiological state into adaptive phenotypic variation of the offspring (Rossiter 1996; Mousseau and Fox 1998a, 1998b). Among these egg components, yolk hormones have received increasing attention, because it has been shown (especially for yolk androgens and to some extent for corticosterone) that they influence numerous phenotypic traits of the offspring. In short, they affect offspring embryonic development, food solicitation behavior (begging), pre- and postnatal growth, sibling competition, immunocompetence, and survival (Eriksen et al. 2003; Rubolini et al. 2005; Hayward et al. 2006; reviewed in Gil 2003; Groothuis et al. 2005). It has been suggested that female birds adjust the hormone levels of their eggs to enhance their fitness through the effects these hormones have on offspring development. According to this idea, mothers deposit hormones in their eggs, which are then taken up by the developing offspring, allowing adaptive adjustment to the current conditions posthatching. Implicitly, control over deposition of hormones and their effects is assigned to the mother, as reflected by frequently used expressions like "golden eggs" (Gil 2003) and "mother knows best" (Schwabl 1998). The question of whether the patterns of hormones in the egg and their effects are adaptive for the mother, the offspring, or both has hardly been discussed. If parental and offspring interests coincide, these questions are irrelevant. However, the evolutionary interests of the mother and offspring do not always coincide: because investment by a mother in an offspring reduces her ability to invest in other current and future offspring, there is parent-offspring conflict over parental investment, with offspring selected to demand 
more resources than their mother is selected to give (Trivers 1974; Godfray 1995, 1999). Parent-offspring conflict is therefore likely to be widespread over the development of offspring: avian mothers will then be selected to modify their deposition of yolk hormones to manipulate offspring development in their own favor, and offspring will be selected to modify their response to maternal yolk hormones to avoid such manipulation. This idea was first raised by Winkler (1993) but has not been widely developed.

Another family member likely to be affected by yolk hormones is the female's partner. While offspring benefit from the parental care provided by both their parents, parents suffer a reduction in future survival and reproductive success depending on their individual effort (Parker et al. 2002). As a result, there is an evolutionary conflict of interest between the parents over care (Trivers 1972; Lessells 1999; Houston et al. 2005). Yolk hormones could play an important role in regulating this conflict, because females might be able to use yolk hormones to modify offspring begging behavior, competitiveness, or developmental rate in a way that increases the male's contribution to parental care.

At first sight, it may seem strange to think of hormones being used to manipulate the receiver against its evolutionary interests. This is because hormones usually act as signals between cells or tissues in the same body that are genetically identical and therefore have the same evolutionary interests (Haig 1996). However, yolk hormones of birds are produced by one genetic individual but act on the receptors of a different, albeit related, genetic individual. Under such circumstances, the sender and receiver are selected to maximize their own fitness by adjusting their signal and response, respectively (Haig 1996).

We therefore believe that maternal hormones may be important in mediating family conflict in birds and that recognition of this will stimulate new and important insights into the role of yolk hormones in ecology and evolution. In discussing this, we will largely refer to androgens because these form the best-studied yolk hormone in birds, but other hormones found in avian eggs such as estrogens, corticosteroids, progestins, or thyroid hormones may be as important (Wilson and McNabb 1997; Schwabl 1998; Hayward and Wingfield 2004; Williams et al. 2005).

\section{Mother-Offspring Conflict: Do Females Manipulate Their Offspring through Yolk Hormones?}

One example where hormones are known to be involved in parent-offspring conflict concerns placental hormones in mammals (Haig 1993, 1996; see also Crespi and Semeniuk 2004). The mammalian fetus releases placental hormones that bind to receptors in the mother's tissues and stimulate nutrient release by the mother. These maternal receptors also respond to hormones of maternal origin. Because the offspring and maternal hormones are molecularly identical, the receptors cannot detect the origin of the signal. Consequently, offspring can, through enhanced placental hormone production, attempt to increase maternal nutrient supply. Mothers may be constrained in the extent to which they can evolve avoidance of fetal manipulation, especially if the receptor performs important functions in the mother's body (Haig 1996). The remarkably high production of placental hormones is thought to be a result of an evolutionary arms race, with offspring increasing their hormonal production and mothers reducing their responsiveness (Haig 1993).

Clearly, the development of the mammalian embryo in the mother's uterus is quite different from that of avian embryos in the egg. While hormones are transferred in both directions between mammalian mothers and offspring, avian embryos cannot influence their mothers via hormone production, because their development takes place in the sealed environment of the egg. Instead, only the mother can shape the hormonal environment experienced by the embryo through the transfer of hormones to the yolk as the egg is formed, and once produced, this signal cannot be modified. Nevertheless, there is potential for an evolutionary arms race like that between mammalian mothers and embryos, but in birds, it is the mother who may use hormonal means to manipulate the embryo and the embryo who may avoid manipulation by evolutionary changes in its responsiveness.

\section{What Is Best for the Mother?}

The accepted explanation for the deposition of yolk hormones by the mother and for variation in the hormone levels both within and between clutches is that they mediate maternal effects that constitute adaptive transgenerational phenotypic plasticity (Mousseau and Fox 1998a, $1998 b$ ). In other words, aspects of the offspring's environment (in its widest sense including the availability of food for provisioning parents; abundance of predators, parasites, and competitors; and position within the hatching sequence in the brood) vary in a way that affects the best way for an offspring to develop. Because the mother may have information about such environmental variation while the offspring initially does not, she can maximize her fitness by communicating the information to the offspring - in essence, telling the offspring the most appropriate way to develop in the environment that it will experience. Yolk hormones are interpreted as the signal by which this communication takes place.

The relevant aspects of the offspring's environment may vary both within and between clutches. For example, the mother's condition or reduced availability of food may 
Table 1: Classification of the fitness costs and benefits contributing to selection acting on deposition of yolk hormones by the mother and development by the offspring

\begin{tabular}{|c|c|c|}
\hline & Source of benefit or cost & Relative weighting in mother and offspring ${ }^{a}$ \\
\hline \multicolumn{3}{|c|}{ Benefits: } \\
\hline 1 & $\begin{array}{l}\text { Increased survival or fecundity of the focal offspring as a result } \\
\text { of hormonally mediated maternal effects in the focal offspring } \\
\text { (dependent or independent of an increase in parental invest- } \\
\text { ment to the focal offspring) }\end{array}$ & Equally weighted in mother and offspring \\
\hline 2 & $\begin{array}{l}\text { Increased survival or fecundity of broodmates of the focal off- } \\
\text { spring as a result of hormonally mediated maternal effects in } \\
\text { the focal offspring (shared benefits) }\end{array}$ & $\begin{array}{l}\text { Weighted at least twice as heavily in the mother } \\
\text { than offspring }\end{array}$ \\
\hline \multicolumn{3}{|c|}{ 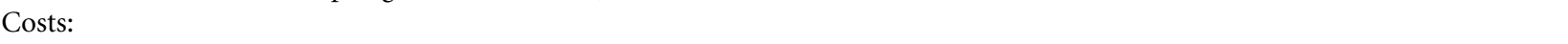 } \\
\hline 1 & $\begin{array}{l}\text { Decreased production of future offspring by the mother } \\
\text { (through reproduced survival or future fecundity) as a result } \\
\text { of increased parental investment }\end{array}$ & $\begin{array}{l}\text { Weighted at least twice as heavily in the mother } \\
\text { than offspring }\end{array}$ \\
\hline 2 & $\begin{array}{l}\text { Decreased survival or fecundity of the focal offspring as a result } \\
\text { of hormonally mediated maternal effects in the focal offspring }\end{array}$ & Equally weighted in mother and offspring \\
\hline 3 & $\begin{array}{l}\text { Decreased survival or fecundity of broodmates of the focal off- } \\
\text { spring as a result of hormonally mediated maternal effects in } \\
\text { the focal offspring (diverted resources and shared costs) }\end{array}$ & $\begin{array}{l}\text { Weighted at least twice as heavily in the mother } \\
\text { than offspring }\end{array}$ \\
\hline 4 & $\begin{array}{l}\text { Decreased production of future offspring by the mother } \\
\text { (through reproduced survival or future fecundity) as a result } \\
\text { of changes to the endocrine system (costs of hormone pro- } \\
\text { duction including leakage into the plasma) }\end{array}$ & $\begin{array}{l}\text { Only contributes to selection on yolk deposition } \\
\text { by the mother }\end{array}$ \\
\hline 5 & $\begin{array}{l}\text { Decreased survival or fecundity of the focal offspring as a result } \\
\text { of changes to the endocrine system (interference with other } \\
\text { developmental processes) }\end{array}$ & $\begin{array}{l}\text { Contributes to selection on development of off- } \\
\text { spring and possibly on yolk deposition by the } \\
\text { mother }\end{array}$ \\
\hline
\end{tabular}

a Assuming that maternal fitness is expressed in terms of the number of offspring produced and that individual offspring fitness is expressed in equivalents of self.

compromise the rate at which the mother can provision the offspring. In this case, she would maximize her fitness if her offspring had a lower target growth trajectory and prioritized efficient resource use during development (e.g., Love et al. 2005). Similarly, if the environment in which the offspring will develop contains many parasites or competitors, the mother might benefit from the offspring diverting resources from growth to immune or territorial defense.

The most important factor generating within-clutch variation in offspring environment is probably position in the hatching sequence. In some species, incubation is begun before the clutch is complete, resulting in asynchronous hatching of the chicks. This in turn creates a competitive hierarchy between the chicks that may result in the death or poor growth of the younger member(s) of the brood (O'Connor 1978; Mock et al. 1990). The discovery of systematic within-clutch variation of androgens led Hubert Schwabl to propose that mothers mediate sibling rivalry by mitigating or reinforcing the effects of hatching asynchrony through the deposition of androgens, thereby maximizing the mother's fitness (Schwabl 1993; for a more detailed discussion, see also Groothuis et al. 2005).
In order to understand the level and patterns of yolk androgen deposition in avian clutches, we need to take into account not only the benefits to the offspring but also a number of costs for both the offspring and the mother (table 1). The relevant costs and benefits, which may be invoked in a number of ways, are those having an effect on fitness. Given the effects of yolk androgens on the begging behavior and competitiveness of chicks (Schwabl 1996; Eising and Groothuis 2003; von Engelhardt et al. 2006), yolk androgens will have costs for the other chicks in a brood and the mother by either diverting food from the other chicks or increasing the effort of the parents. Hormones may also be costly for the mother to produce. At first sight, such costs seem small: yolk hormones are produced in tiny amounts, so the energy used in their production will be negligible. Moreover, the precursor to steroid hormones is cholesterol, which is freely available in the mother's body (Nelson 2005). However, the production of yolk hormones may have important fitness costs for the mother if the female cannot regulate hormone levels in the yolk and her own plasma independently (a pleiotropic effect; Groothuis et al. 2005). If this is the case, variation in yolk hormone levels would engender changes in the female's plasma levels, which might invoke costs 
through their effects on maternal physiology and behavior (e.g., Rutkowska et al. 2005; reviewed in Ketterson et al. 2005). The female's optimal level of yolk hormone would then depend on those costs as well. If, on the other hand, yolk and plasma levels can be regulated independently, the fitness consequences of plasma hormone levels for the female are irrelevant to selection on yolk hormone levels. This needs to be considered separately for each hormone because the extent to which different hormones can be regulated independently in yolk and plasma and their effect on maternal physiology may vary.

Given that the leakage of hormones between yolk and plasma could invoke important fitness costs to yolk hormone deposition, it is obvious that knowing whether avian mothers can independently regulate plasma and yolk hormone levels is critically important to understanding yolk hormone levels from an evolutionary perspective. We would therefore like to encourage studies investigating the regulation of hormone transfer to the egg. Some studies have shown that hormone implantation of female birds during laying leads to increased yolk hormone levels, suggesting that hormones diffuse from within the mother to the egg (Adkins-Regan et al. 1995; Hackl et al. 2003; Clotfelter et al. 2004; Rutkowska et al. 2005; Williams et al. 2005). However, implants usually lead to comparatively high plasma hormone levels, which may indeed lead to leakage into the egg. This may not reflect the natural situation, because the most important source of the hormones that are secreted into the egg is probably the follicular wall rather than the maternal plasma (Shahabi et al. 1975; Bahr et al. 1983; Tilly and Johnson 1989), except for corticosterone and thyroid hormones that are probably produced exclusively in the adrenals and the thyroid, respectively. A better way to study the transfer of steroid hormones may be direct stimulation of steroid hormone production in the follicles using gonadotrophic hormones in order to measure how tightly hormone release into the plasma and eggs are linked and to study the factors that modulate the release into the plasma versus eggs. Some evidence suggests active regulation of hormone transfer to the egg: relative levels of different hormones can be very different in the egg compared with the plasma (Navara et al. 2006). For example, at the time of laying, plasma levels of estradiol and testosterone are often similar (e.g., Williams et al. 2004), whereas yolk estradiol levels are less than one-hundredth of yolk testosterone levels and frequently almost undetectable (Groothuis et al. 2005). The low transfer of estradiol may relate to the fact that estradiol plays a major role during sexual differentiation, which can be severely affected by any change in its concentration (e.g., Adkins 1975; Wade et al. 1997). However, this does not show unequivocally that levels of a single hormone can be regulated independently in plasma and yolk: the same difference in relative levels of different hormones in plasma and yolk could be produced by differences in either the site of production or rates of diffusion or degradation. The question of whether plasma and yolk hormone levels can be regulated independently therefore remains open.

\section{A Different Perspective: What Is Best for the Offspring?}

The previous section sees maternal effects mediated by yolk hormones as a single relationship (fig. 1c), under the control of the mother, between offspring development and the environment in which it develops. It assumes that the way in which the developing offspring is influenced by yolk hormones cannot vary evolutionarily. In fact, the relationship between offspring development and the environment is determined by two relationships (fig. 1). The first is the relationship between the amount of hormone deposited by the mother and the environment, which depends on the physiology of the mother and is presumably under the control of genetic loci that are expressed in the mother. However, the second is the relationship between offspring development and the amount of yolk hormones deposited by the mother, which depends on the physiology involved in the development of the offspring and is presumably under the control of a different set of genetic loci that are expressed in the offspring. Mutations of such genes would therefore alter the relationship between offspring development and the environment (fig. 1c) by altering the relationship between offspring development and the amount of yolk hormones (fig. $1 b$ ).

Relationships of the type shown in figure $1 a$ and $1 b$ are known as reaction norms. They depend on details of development and physiology, which in turn depend on underlying genetic loci. If there is genetic variation in these loci, there will be genetic variation in the resulting reaction norm. Selection acting on genetically variable loci that affect the interactions between relatives (including those involved in the reaction norms for deposition of, and response to, yolk hormones) results in indirect genetic effects (e.g., Cheverud and Moore 1994; Moore et al. 1998; Kölliker et al. 2005; Moore and Pizzari 2005). In this article, we have not elaborated on the effects of genetic variation in reaction norms for two reasons. First, from a pragmatic viewpoint, little is known about the heritability of either yolk hormone deposition or offspring response to yolk hormones and even less about genetic covariance between maternal yolk hormone deposition and the offspring response, so data are not available to test recent theoretical predictions (e.g., Kölliker et al. 2005). However, we can be certain that at least part of the observed variation in yolk hormone deposition is the result of phenotypic plasticity (as reflected in a reaction norm) because there is within-female variation in hormone deposition (e.g., in 


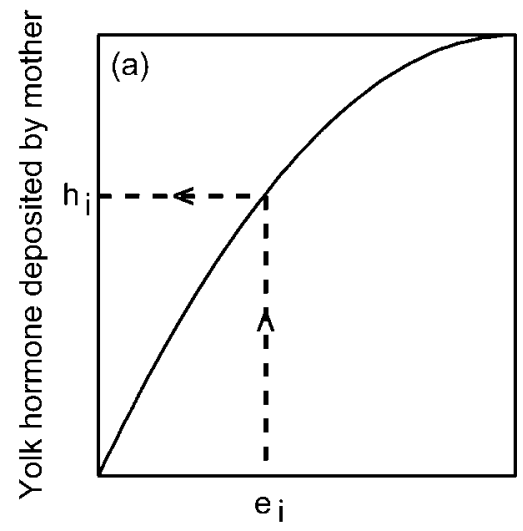

Environment

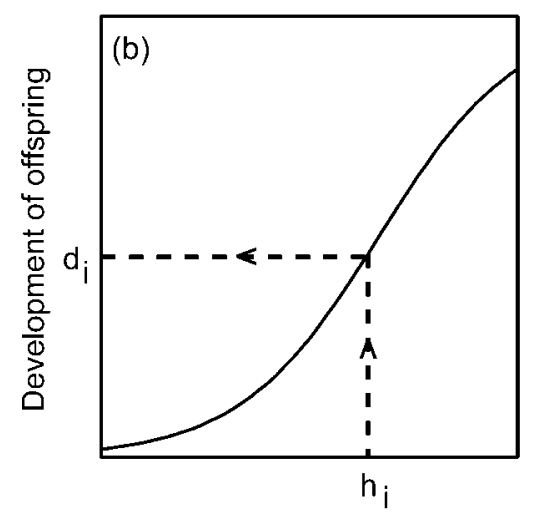

Yolk hormone deposited by mother

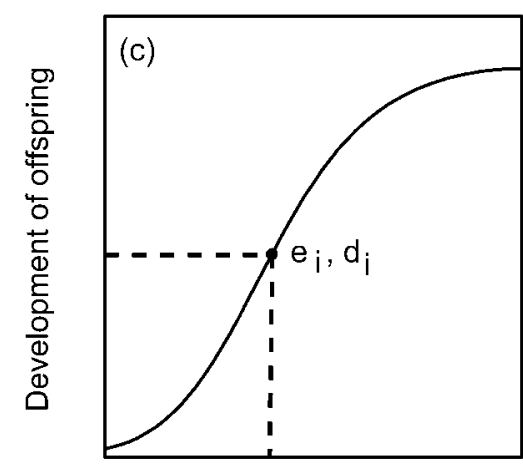

Environment

Figure 1: Taken together, the relationship between yolk hormone deposition by the mother and the environment ( $a$ ) and the relationship between the development of the offspring and the yolk hormone deposition by the mother $(b)$ determine the relationship between the development of the offspring and the environment $(c)$. For example, if, in environment $e_{i}$, the mother deposits an amount $h_{i}$ of yolk hormone and the offspring responds to an amount $h_{i}$ of yolk hormone with development $d_{i}$, then $e_{i}, d_{i}$ is one pair of points on the curve relating offspring development to the environment. The whole of curve $c$ can be built up by considering different initial values of $e$, the environment, and then using curve $a$ to find the value of $h$, the amount of yolk hormone deposited by the mother, and curve $b$ to find the consequent value of $d$, the development of the offspring. Evolution of curve $c$ can be brought about by mutations of genes expressed in the mother that determine the shape of curve $a$ or by mutations of genes expressed in the offspring that determine the shape of curve $b$.

relation to position in the laying sequence) and because females change the amount of yolk hormones deposited in response to some experimental changes in the environment (e.g., in mate attractiveness or social density; reviewed in Groothuis et al. 2005). Second, our primary goal in this article is to discuss the way in which selection arises from the physiological interaction resulting from the mother's deposition of, and the offspring's response to, yolk hormones - in particular, the occurrence of antagonistic selection in mothers and offspring (parent-offspring conflict) and male and female parents (sexual conflict)and how the mother's and offspring's reaction norms evolve in response to this. Models of indirect genetic effects are not well suited to this purpose: selection is reduced to selection gradients (e.g., Wolf et al. 1999), giving little insight into the processes giving rise to the selection, and indirect genetic effects models assume that the interaction coefficients that correspond with reaction norms are constant (e.g., Moore et al. 1998; Kölliker et al. 2005; Moore and Pizzari 2005; but see Kölliker 2005), whereas we are interested in how these reaction norms will evolve.

Variation in the response of offspring to maternal yolk hormones (fig. $1 b$ ) could be mediated through (a) up- or downregulation of receptor density, $(b)$ inactivation of maternal hormones as they are metabolized, $(c)$ selective uptake of substances from the yolk, or $(d)$ an increase or decrease of endogenous hormone production. Evidence for such processes is provided by variation in hormone receptor expression in different tissues of avian embryos (Godsave et al. 2002), the changes in sex steroid levels in yolks during embryonic development (Elf and Fivizzani 2002; Eising et al. 2003), and variation in embryonic hormone production (Woods et al. 1971; Bruggeman et al. 2002).

If such modification in the way that offspring develop in relation to the level of yolk hormones is possible, it is worthwhile to consider the factors that influence the optimal development for the offspring (table 1). Just as for the mother, the relevant costs and benefits determining the optimal development in response to yolk hormones are those having an effect on offspring fitness. One group of costs and benefits is the same as for the mother (although weighted differently in calculation of the optimal development; see below; table 1). These are the costs and benefits that are invoked by the change in offspring development brought about by the yolk hormones: the individual offspring may gain a benefit in terms of increased survival or fecundity, but these changes also carry fitness costs for it. For example, an increase in the competitiveness of an individual chick will be beneficial for the chick itself but will either divert food and other forms of parental care from the other chicks in the brood or increase the effort of the parents in caring for the brood. Both of these will carry costs to an individual offspring's inclusive fitness by reducing the number of surviving siblings produced from the current brood or from future broods. 
The other group of costs that need to be taken into account when calculating the optimal relationship for an offspring between its development and the amount of yolk hormones is those incurred by changes to the endocrine system interfering with other developmental processes. For example, a change in receptor densities or endogenous hormone production may incur costs because the same hormones (androgens and estrogens) and receptors are involved in sexual differentiation (Balthazart and AdkinsRegan 2003). Similarly, prenatal hormone exposure can have lifelong consequences, for example, by affecting adult reproductive behavior (Clark and Galef 1995; for birds, see Groothuis et al. 2005). Such organizational changes could also incur costs that need to be taken into account.

One important issue is which of the costs incurred directly by the endocrine system (costs of hormone production in the mother; interference with other developmental processes in the offspring) will have an effect on the mother's or the offspring's optima. The answer is those costs that are changed as the relevant traits of the mother and offspring are changed (e.g., by mutation). For the mother, the relevant costs are those that change as the amount of yolk hormone deposited changes. This potentially includes costs of yolk hormone production and costs incurred by the offspring's endocrine system. However, the latter costs will affect only the mother's optimal reaction norm for yolk hormone deposition (fig. 1a) if the extent of interference with developmental processes in the offspring depends on the amount of hormone deposited (i.e., a quantitative effect). For the offspring, the relevant costs are those that change as the offspring's development in response to a given level of hormone changes. This includes any interference with developmental processes but does not include the costs of yolk deposition incurred in the mother, because the level of hormone deposited is not changed by a mutational change in offspring development (although this will change the selection on the mother's pattern of yolk deposition).

So far, we have considered yolk hormones as acting essentially as a signal, with the offspring free to modify their response on an evolutionary timescale. However, if a particular maternally derived hormone is essential for some aspect of the chick's development and the offspring is unable to manufacture the hormone itself (e.g., early in development), the hormone would be acting as a resource, and the mother could impose her optimum by depriving the chick of sufficient resource to achieve its optimum. However, it is difficult to imagine hormones acting in this way, and we know of no examples. Moreover, the hormone would nevertheless transmit information to the offspring about its environment. Although the offspring would suffer from the limited resource availability, they could still evolutionarily modify other aspects of their development that were not dependent on the same resource or vary the relative allocation of the resource to different components of their development to achieve their optimal development in their anticipated future environment under the prevailing resource constraints. In other words, the mothers could control only the total amount of resources provided to the offspring, while the offspring can still control how these are allocated. It is therefore hard to see how mothers could ever completely impose their optimum on offspring. (The same can be said of any resource [e.g., carotenoids] that is supplied by the parents to the offspring.)

This section has emphasized a number of ways in which the endocrine system of the offspring may affect the fitness costs and benefits of how offspring respond to maternal yolk hormones and hence how this relationship will evolve. Questions regarding the mechanisms that influence how the offspring respond to yolk hormones are especially pressing in understanding the evolution of maternal effects mediated by yolk hormones. Such questions include the following: If the response to maternal hormones can vary, what are the components of the endocrine system that are modified? And to what extent does this variation invoke costs by interfering with other aspects of development such as sexual differentiation? Such questions could be approached using, for example, selection experiments.

\section{When Is There Mother-Offspring Conflict?}

In the previous two sections, we have argued that the relationship between offspring development and the environment is not a single relationship (fig. 1c) under the control of the mother but rather the outcome of two relationships: that between the amount of yolk deposited and the environment (fig. 1a) and that between the development of an offspring and the amount of yolk hormones (fig. $1 b$ ). We also considered the fitness costs and benefits that would affect the mother's and the offspring's optimal relationships (table 1). In this section, we consider when there will be parent-offspring conflict over maternal effects mediated by yolk hormones.

Parent-offspring conflict occurs by definition when selection acts antagonistically in parents and their offspring. In the case of yolk hormones, parent-offspring conflict would mean that when the mother's relationship between environment and yolk deposition is optimal for her, the relationship between offspring development and yolk hormones is suboptimal for the offspring, and vice versa. Mother-offspring conflict over maternal effects mediated by yolk hormones (and more generally over all maternal effects) is expected to be common. This is because changes in offspring development-such as in response to yolk hormones-will nearly always bring about a change in parental investment (e.g., in how long the parents have to 
incubate or how much they have to feed), defined as any form of parental care that produces a fitness benefit in an offspring while carrying a fitness cost to the parent. These two effects on fitness-a benefit to the offspring and a cost to the mother (expressed as a decrease in fitness through other offspring)-impinge on the optimal responses of both the mother to the environment and the offspring to yolk hormones (see above; table 1). However, the relative weighting of these costs and benefits differs between the mother and offspring: essentially, whereas the mother is equally related to all her current and future offspring and therefore weights costs and benefits to each of them equally, offspring are at least twice as related to themselves than they are to both their current and future siblings (for a detailed consideration of the relative weightings, see Lessells and Parker 1999). Offspring therefore weight the costs and benefits to themselves more heavily than those to their siblings. As a result, whenever a change in offspring development diverts resources from current or future (via costs to the mother) siblings, there will be mother-offspring conflict. The cases where this does not occur are probably rather rare: an imaginary example would be if offspring coloration provided camouflage protection against predators, but there were no differential costs for the offspring of developing different coloration. In this case, the optimal offspring coloration (matched with the current background) would be the same for mother and offspring.

Although the mother's and offspring's optimal offspring development may differ, the actual magnitude of the difference may not be great. As a result, determining experimentally whether the mother or offspring "wins" in mother-offspring conflict will require rather careful quantitative predictions. To establish whether hormone patterns in clutches are optimal to offspring and/or the mother, it will be necessary to experimentally manipulate yolk hormone patterns and measure the fitness consequences for both offspring and mother. This could be done by a combination of hormone injections in eggs and swaps between clutches of eggs containing different endogenous and manipulated hormone concentrations.

\section{What Will Be the Evolutionary Resolution of Mother-Offspring Conflict?}

When there is mother-offspring conflict over offspring development, the offspring's optimal development is, by definition, different from the mother's. Mothers are selected to deposit levels of yolk hormones that cause the chick to develop according to the mother's optimum. However, when this is the case, the chicks are selected to modify the way that they respond to yolk hormones so that they achieve their optimal development. This in turn will select mothers to change the level of yolk hormones they deposit to compensate for the changed responsiveness of embryos so that they, the mothers, are once again achieving their optimal offspring development. In essence, there is reciprocal selection between mothers and offspring for mothers to attempt to manipulate the chicks and for chicks to offset the attempt at manipulation. Such reciprocal selection pressures can lead to an evolutionary arms race, as seems to occur over placental hormones in mammals (Haig 1993).

If an evolutionary arms race does start, where will it end? A similar evolutionary arms race is thought to occur between parents and offspring over begging displays. In the case of begging, the offspring transmits information to the parent about its current hunger level, which determines the optimal amount of provisioning of the young, over which there is parent-offspring conflict. In the case of yolk hormones, the mother transmits information to the offspring about environmental conditions, which determine the optimal offspring development, over which there is usually parent-offspring conflict. There is thus an analogy between maternal yolk hormones and begging in that both involve an interaction between a parent and offspring, in which one individual (the mother in the case of yolk hormones and the offspring in the case of begging) has information that affects the fitness consequences of behavior by the other (development by the offspring in the case of yolk hormones and provisioning by the parent in the case of begging). The result of such an interaction for begging is that the chicks are selected to exaggerate their need to the parents and the parents are selected to downplay their response to begging. Theoretical models suggest that the resultant arms race may be brought to a halt if there are costs to the begging display (Godfray 1991; Johnstone and Godfray 2002). Paradoxically, the models suggest that, although it is the offspring that have the relevant information (how hungry they are), at the evolutionary equilibrium, it is the parents who achieve their optimal provisioning level (although the fitness of both parents and offspring suffer from the costs of begging; but see Johnstone 1996). We speculate by analogy that, in the case of yolk hormones, it will be the costs of hormone production for the mother that stabilize the evolutionary arms race and that, although it is the mother that has the relevant information (what the offspring environment will be), at the evolutionary equilibrium it is the offspring who achieve their optimal development (although the fitness of both parents and offspring suffer from the costs of hormone production). If we are right about the costs of hormone production stabilizing the mother-offspring interaction via yolk hormones, understanding whether yolk and plasma levels of hormones can be independently regulated becomes increasingly pertinent. 
In the analogy between yolk hormones and begging, the costs of hormone production by the mother are analogous to the costs of begging in the offspring. However, in the models of begging, changes in the response by the parent to begging are assumed not to incur costs through changes in the parent's response mechanism (as would occur, for example, if a change in responsiveness also applied to other stimuli than begging, with negative consequences for maternal fitness). In contrast, as we pointed out above, changes in the response of embryos to yolk hormones may well incur costs through changes to the chick's endocrine system. In this respect, the analogy with begging breaks down. Without knowing more about the fitness consequences of changes to the chick's endocrine response, we cannot say more about the effect of these costs on the resolution of mother-offspring conflict.

\section{Sibling Competition}

Sibling conflict arises through the same relatedness asymmetries as parent-offspring conflict: individual offspring are more related to themselves than to their siblings (Mock and Parker 1997; Parker et al. 2002). Sibling competition originates through sibling conflict and has been a major focus of interest since the first studies of maternal yolk hormones in birds. Variation in yolk hormones across the laying sequence, which was one of the first patterns described (Schwabl 1993), has been interpreted as a mechanism for the mother to individually adjust survival probabilities of her offspring to mitigate or enhance the effects of hatching asynchrony (Schwabl 1993; see also Groothuis et al. 2005). It is surprising that little consideration has been given to active strategies of the offspring in this conflict. In the context of hatching asynchrony, mother and offspring may disagree over brood reduction, with the conditions over which a runt should sacrifice itself for the benefit of its siblings being more limited than those where it pays the mother to impose brood reduction on the runt (O'Connor 1978; Mock and Parker 1997). For instance, it has been proposed (Schwabl et al. 1997) that high yolk androgen levels in the first laid eggs of cattle egrets could enhance the effects of hatching asynchrony and thereby facilitate brood reduction. This raises the question of why the younger chicks in a brood do not evolve to be competitive even when experiencing low yolk androgen levels.

The extent of sibling rivalry will also depend on whether the costs and benefits of hormone-mediated behavior by any chick are felt by that chick alone or by the whole brood. For example, when an individual chick begs more, that chick may be fed more (an individual benefit), or, at the other extreme, the parents may bring more food but divide it between the offspring without reference to the begging behavior (a brood benefit). Similarly, the costs of begging may fall on the chick that is begging or on the whole brood. For example, begging might attract nestling predators. At one extreme, predation risk for each chick may depend only on how much it has begged (an individual cost), or, at the other extreme, predators attracted to the brood might take them all (or some of them at random with respect to their individual begging, a brood cost). Individual costs and benefits will tend to maximize sibling conflict, while sibling conflict is abolished if all costs and benefits are felt by the brood (although parentoffspring conflict remains).

Most studies on the function of maternal yolk hormones report on individual costs and benefits (Gil 2003; Groothuis et al. 2005), and individual benefits are often at the cost of siblings (Eising et al. 2001). However, most studies have neglected the possibility that some hormonally affected traits could benefit the whole brood. We therefore want to emphasize the need for studies investigating nestling behavior such as defense against predation and territorial behavior in semiprecocial colonial species, which could be affected by yolk hormones and yield benefits that are shared by the brood. Equally, studies are needed to determine whether the benefits of enhanced parental feeding rates mediated by yolk androgens are felt individually or by the whole brood (e.g., Bengtsson and Rýden 1983).

Another factor that can influence parent-offspring and sibling conflict is variation in relatedness among family members as a result of extrapair paternity. Extrapair paternity will reduce average relatedness between broodmates (unless the entire brood is fathered by a single extrapair male) and reduce the relatedness between offspring and their social father while leaving that between offspring and their social mother unchanged. Reduced relatedness selects for a higher level of sibling competition, which is not in the interest of the mother (Hamilton 1964). Comparative studies have shown that begging intensity (Briskie et al. 1994) and growth rate (Royle et al. 1999) are both positively associated with the average level of extrapair paternity (Briskie et al. 1994; Royle et al. 1999). Both these traits can be affected by embryonic exposure to maternal yolk hormones (Gil 2003; Groothuis et al. 2005). Here we propose that the yolk hormone concentrations in species with high levels of extrapair paternity should be lower in order to reduce the level of sibling competition. At the same time, the responsiveness of offspring toward these hormones should increase. This area clearly represents a fruitful avenue for further research.

\section{Sexual Conflict: Do Females Manipulate Their Mates through Yolk Hormones?}

In addition to the role of mother-offspring conflict in driving the evolution of mammalian placental hormones, 
sexual conflict has also been identified as an important selection pressure (e.g., Moore and Haig 1991). In mammals, fathers face minimal investment costs during embryogenesis and lactation and, unless the female's investment impinges on the male's own future fitness, are selected to extract maximum resources from the mother (Moore and Haig 1991; Lessells and Parker 1999; Lessells 2006). One mechanism to achieve this seems to be the phenomenon of genomic imprinting, whereby only paternally derived alleles are expressed at loci that increase resource transfer from the mother to the embryo, while at "counterplayer" loci-those reducing resource transfer to the offspring-only maternally derived alleles are expressed (Moore and Haig 1991; Tilghman 1999; Hitchins and Moore 2002; Constãncia et al. 2004). Birds do not have the intimate interaction between embryo and mother found in mammals. The resources available to the embryo are fixed before the egg is laid and set an unbreakable limit to embryonic growth. This may be the reason why genomic imprinting has not been found for genes affecting the development of avian embryos (e.g., O'Neill et al. 2000; Nolan et al. 2001). Recently, it has become evident that imprinted genes in mammals also affect postnatal motheroffspring interactions until weaning (Lefebvre et al. 1998; Li et al. 1999), suggesting that similar processes could operate as a mechanism of sexual conflict in birds (see also Tuiskula-Haaivisto et al. 2004; Minivielle et al. 2005). However, here we would like to focus on the potential role of yolk hormones in sexual conflict.

Whereas in mammals it is the males who manipulate females into increasing investment, we want to highlight the possibility that avian yolk hormones offer a mechanism by which females in species with biparental care or uniparental male care may manipulate their males into increasing care. Because of parental sex differences in the way that care is provided, females may increase male parental investment by modifying begging behavior, competitiveness, and/or pre- and postnatal growth of their offspring through the transfer of hormones to the egg. For example, in some species, males and females react differently to offspring begging signals, or various forms of brood division occur: males and females feed young of different ages or sizes, feed from different positions, or feed differently in relation to hatching asynchrony or brood sex ratio (Slagsvold 1997; Lessells 2002). Through the effects of yolk hormones on offspring begging behavior and competitiveness (Gil 2003; Groothuis et al. 2005), females may create offspring that stimulate more male parental investment. Table 2 summarizes evidence for sex differences in the parental response to specific begging traits that could be affected by maternal yolk hormones. However, knowledge of how parents integrate and respond to different components of begging displays is limited.
Only a few studies have included a sufficiently detailed analysis of begging behavior to allow conclusions on the impact of maternal yolk hormones. Among the four studies that have investigated begging behavior in relation to embryonic androgen exposure (Schwabl 1996; Eising and Groothuis 2003; Pilz et al. 2004; von Engelhardt et al. 2006), none measured the parental response. At the moment, the most promising species for further studies is the canary, for which both sex differences in feeding rules and yolk androgen-dependent begging behavior have been reported (Schwabl 1996; Kilner 2002b), suggesting that a combined study of these effects would be rewarding. In addition, there is some evidence that female great tits respond more to vocal cues, while males respond more to the visual cue of the gape (Christe et al. 1996; Kölliker et al. 2000; Hinde in Kilner 2002a; but see Hinde 2006), making great tits an appropriate study species too.

Females could also affect the relative parental investment by speeding up or delaying offspring prenatal growth rate (Sockman and Schwabl 2000; Eising et al. 2001; von Engelhardt et al. 2006). If males contribute more to synchronous broods, as suggested by the reduced survival of males caring for experimentally synchronized blue tit broods (Slagsvold et al. 1994; see also Slagsvold et al. 1995), females may reduce their own effort by increasing hatching synchrony. Finally, males frequently feed larger or older young (Slagsvold 1997; Lessells 2002), so that enhanced nestling growth may lead to increased male investment. Sex differences in parental care create considerable potential for female manipulation of male parental care through the specific effects of yolk hormones. Even if males and females respond similarly to begging signals, females may increase the male's contribution to parental care through what has been called a "self-imposed handicap" (Houston et al. 2005). High hormone levels in the egg may increase the food requirements of the young through their effects on growth, competition, or begging. If the costs of reproduction vary in males and females, males may be selected to increase their share of parental care in response to this increased need. However, males are not expected to respond passively; they are expected to counter by evolving a more specific response to offspring begging or by ignoring those components of begging that are modified by maternal hormones. In this case, sex differences in parental provisioning rules could arise as the result of sexual conflict rather than being a cause of such differences (in the sense that they offer females an opportunity to manipulate males independently of their own provisioning behavior). Future experimental studies that manipulate yolk hormone concentration should investigate possible sex differences in the parental response, which will yield new and important information on the adaptive significance of maternal yolk hormones. However, these studies need to take 
Table 2: Review of studies investigating sex differences in parental feeding in relation to begging behavior

\begin{tabular}{|c|c|c|c|c|}
\hline $\begin{array}{l}\text { Trait } \\
\text { investigated }\end{array}$ & $\begin{array}{l}\text { Responding } \\
\text { sex }\end{array}$ & Design and/or study outcome & Species & Source \\
\hline Begging & Both & $\begin{array}{l}\text { Both parents and helpers increased care } \\
\text { in response to playback }\end{array}$ & $\begin{array}{l}\text { Arabian babbler Turdoides } \\
\text { squamiceps }\end{array}$ & Wright 1998 \\
\hline Begging & Both & $\begin{array}{l}\text { Both parents increased care in response } \\
\text { to playback }\end{array}$ & $\begin{array}{l}\text { Red-winged blackbird Agelaius } \\
\text { phoeniceus }\end{array}$ & Burford et al. 1998 \\
\hline Begging first & Both & $\begin{array}{l}\text { Both parts fed according to competitive } \\
\text { hierarchy }\end{array}$ & Tree swallow Tachycineta bicolor & Whittingham et al. 2003 \\
\hline Begging & Female & $\begin{array}{l}\text { Females responded to more traits and } \\
\text { to hunger level }\end{array}$ & Canary Serinus serinus & Kilner $2002 b$ \\
\hline Begging calls & Female & $\begin{array}{l}\text { Females responded to begging, indicat- } \\
\text { ing nutritional state }\end{array}$ & $\begin{array}{l}\text { Manx shearwater Puffinus } \\
\text { puffinus }\end{array}$ & Quillfeldt et al. 2004 \\
\hline Begging calls & Female & $\begin{array}{l}\text { Females increased care in response to } \\
\text { playback of begging calls }\end{array}$ & Great tit Parus major & Kölliker et al. 2000 \\
\hline Unknown & Female & $\begin{array}{l}\text { Females decreased care more strongly } \\
\text { for food-supplemented chicks }\end{array}$ & American kestrel Falco sparverius & Dawson and Bortolotti 2002 \\
\hline Begging & Male & $\begin{array}{l}\text { Playback of begging calls had a stronger } \\
\text { effect on male care }\end{array}$ & $\begin{array}{l}\text { Pied flycatcher Ficedula } \\
\text { hypoleuca }\end{array}$ & Ottosson et al. 1997 \\
\hline Begging & Male & $\begin{array}{l}\text { Males increased feeding to broods that } \\
\text { begged more }\end{array}$ & $\begin{array}{l}\text { Budgerigar Melopsittacus } \\
\text { undulatus }\end{array}$ & Stamps et al. 1985, 1987 \\
\hline Begging calls & Male & $\begin{array}{l}\text { Males increased care in response to } \\
\text { playback of begging calls }\end{array}$ & $\begin{array}{l}\text { Superb fairy wren Malurus } \\
\text { cyaneus }\end{array}$ & MacGregor and Cockburn 2002 \\
\hline Begging rate & Male & $\begin{array}{l}\text { Males increased feeding rate for young } \\
\text { of lower condition }\end{array}$ & Great tit $P$. major & Christe et al. 1996 \\
\hline Posture & Male & Males responded to posture only & Canary S. serinus & Kilner $2002 b$ \\
\hline Posture & Male & $\begin{array}{l}\text { Females decreased in responsiveness to } \\
\text { posture over nestling age }\end{array}$ & Canary S. serinus & Kilner $2002 b$ \\
\hline Gaping & Male & $\begin{array}{l}\text { Males responded to visual, females to } \\
\text { visual and vocal display }\end{array}$ & Great tit $P$. major & Clark and Lee 1998 \\
\hline Unknown & Male & $\begin{array}{l}\text { Males increased care for food-supple- } \\
\text { mented chicks }\end{array}$ & House sparrow Passer domesticus & Hinde in Kilner $2002 a$ \\
\hline Begging & None & $\begin{array}{l}\text { Females fed more unevenly compared } \\
\text { with males }\end{array}$ & Pied flycatcher F. hypoleuca & Mock et al. 2005 \\
\hline Begging calls & None & $\begin{array}{l}\text { Playback of begging did not increase } \\
\text { feeding rate in either sex }\end{array}$ & $\begin{array}{l}\text { Red-winged blackbird } A \text {. } \\
\text { phoeniceus }\end{array}$ & Gottlander 1987 \\
\hline
\end{tabular}

into account that parents may respond to each other's feeding effort (e.g., Hinde 2006) so that changes in their feeding behavior may not be exclusively due to variation in offspring solicitation (Kölliker and Richner 2001).

\section{Conclusions and Future Directions}

We suggest that current thinking on the function of avian yolk hormones overemphasizes the view that it is the mother who maximizes her fitness by adjusting offspring development to given environmental conditions. Although the offspring may benefit from adjusting their development in response to hormonal signals from the mother, because the mother may have information on the environment that is useful for the offspring, the evolutionary interests of the mother and offspring do not always coincide. Furthermore, parents disagree evolutionary over the amount of care each of them is willing to provide, and females may therefore try to manipulate their mate by modifying offspring behavior through yolk hormone deposition, shifting the division of labor in their favor.
We believe that a full understanding of hormonemediated maternal effects may be achieved only if both evolutionary conflicts of interest and endocrine mechanisms are taken into account. As we have emphasized above, specific details of the endocrine mechanisms that are involved are crucial to an evolutionary understanding of maternal effects mediated by yolk hormones. This applies not only to the relationship between the amount of hormones deposited and the environment, which depends on the maternal endocrine system, but also to the relationship between offspring development and the amount of maternal hormones deposited, which depends on the endocrine system of the offspring. Endocrinologists may gain insights from a flow of these ideas in the opposite direction, from evolutionary biology to endocrinology: the systems they work on usually involve endocrine signaling between cells and tissues that are genetically identical. As a result, there are no evolutionary conflicts of interest between the signaler and receiver, and the system is expected to evolve to maximum efficiency. However, we have argued that when the signaler and receiver are not genet- 
ically identical, some aspects of hormone production by the mother and of the response to hormones by the embryo may make sense only in the light of evolutionary conflicts of interest. One could therefore be sorely misled by expecting maximum efficiency when investigating the signaling system. In conclusion, we believe that the integration of evolutionary biology and endocrinology will lead to the most rapid advance in the understanding of hormone-mediated maternal effects from both an evolutionary and endocrinological point of view.

\section{Acknowledgments}

This article was stimulated by the European Science Foundation/National Science Foundation/Natural Sciences and Engineering Research Council funded network Adaptations and Constraints in Avian Reproduction: Integrating Ecology and Endocrinology. W.M. was supported by a postdoctoral grant from the Fonds voor Wetenschappelijk Onderzoek Flanders (Belgium). We thank three anonymous reviewers for their helpful and constructive comments.

\section{Literature Cited}

Adkins, E. 1975. Hormonal basis of sexual differentiation in Japanese quail. Journal of Comparative and Physiological Psychology 89: 61-71.

Adkins-Regan, E., M. A. Ottinger, and J. Park. 1995. Maternal transfer of estradiol to egg yolks alters sexual differentiation of avian offspring. Journal of Experimental Zoology 271:466-470.

Bahr, J. M., S. C. Wang, M. Y. Huang, and E. O. Calvo. 1983. Steroid concentrations in isolated theca and granulosa layers of preovulatory follicles during the ovulatory cycle of the domestic hen. Biology of Reproduction 29:326-334.

Balthazart, J., and E. A. Adkins-Regan. 2003. Sexual differentiation of brain and behavior in birds. Pages 223-301 in D. Pfaff, A. Arnold, A. Etgen, S. Fahrbach, and R. Rabin, eds. Hormones, brain and behavior. Vol. 4. Elsevier, The Netherlands.

Bengtsson, H., and O. Rýden. 1983. Parental feeding rate in relation to begging behaviour in asynchronously hatched broods of the great tit Parus major. Behavioral Ecology and Sociobiology 12:243251.

Briskie, J. V., C. T. Naugler, and S. M. Leech. 1994. Begging intensity of nestling birds varies with sibling relatedness. Proceedings of the Royal Society B: Biological Sciences 258:73-78.

Bruggeman, V., P. van As, and E. Decuypere. 2002. Developmental endocrinology of the reproductive axis in the chicken embryo. Comparative Biochemistry and Physiology A 131:839-846.

Burford, J. E., T. J. Friedrich, and K. Yasukawa. 1998. Response to playback of nestling begging in the red-winged blackbird Aegelaius phoenicus. Animal Behaviour 56:555-561.

Cheverud, J. M., and A. J. Moore. 1994. Quantitative genetics and the role of environment provided by relatives in the evolution of behavior. Pages 67-100 in C. R. B. Boake, ed. Quantitative genetic studies of behavior. University of Chicago Press, Chicago.

Christe, P., H. Richner, and A. Oppliger. 1996. Begging, food provisioning, and nestling competition in great tit broods infested with ectoparasites. Behavioral Ecology 7:127-131.
Clark, A. B., and W. H. Lee. 1998. Red-winged blackbird females fail to increase feeding in response to begging call playbacks. Animal Behaviour 43:729-745.

Clark, M. M., and B. G. Galef Jr. 1995. Prenatal influences on reproductive life history strategies. Trends in Ecology \& Evolution 10:151-153.

Clotfelter, E. D., D. M. O’Neal, J. M. Gaudioso, J. M. Casto, I. M. Parker-Renga, E. A. Snajdr, D. L. Duffy, V. Nolan Jr., and E. D. Ketterson. 2004. Consequences of elevating plasma testosterone in females of a socially monogamous songbird: evidence of constraints on male evolution? Hormones and Behaviour 46:171-178.

Constãncia, M., G. Kelsey, and W. Reik. 2004. Resourceful imprinting. Nature 432:53-57.

Crespi, B., and C. Semeniuk. 2004. Parent-offspring conflict in the evolution of vertebrate reproductive mode. American Naturalist 163:635-653.

Dawson, R. D., and G. R. Bortolotti. 2002. Experimental evidence for food limitation and sex-specific strategies of American kestrels (Falco sparverius) provisioning offspring. Behavioral Ecology and Sociobiology 52:43-52.

Eising, C. M., and T. G. G. Groothuis. 2003. Yolk androgens and begging behavior in black-headed gull chicks: an experimental field study. Animal Behaviour 66:1027-1034.

Eising, C. M., C. Eikenaar, H. Schwabl, and T. G. G. Groothuis. 2001. Maternal androgens in black-headed gull (Larus ridibundus) eggs: consequences for chick development. Proceedings of the Royal Society B: Biological Sciences 268:839-846.

Eising, C. M., W. Müller, C. Dijkstra, and T. G. G. Groothuis. 2003. Maternal androgens in egg yolks: relation with sex, incubation time and embryonic growth. General and Comparative Endocrinology 132:241-247.

Elf, P. K., and A. J. Fivizzani. 2002. Changes in sex steroid levels in yolks of the leghorn chicken, Gallus domesticus, during embryonic development. Journal of Experimental Zoology 293:594-600.

Eriksen, M. S., A. Haug, P. A. Torjesen, and M. Bakken. 2003. Prenatal exposure to corticosterone impairs embryonic development and increases fluctuating asymmetry in chickens (Gallus gallus domesticus). British Poultry Science 44:690-697.

Gil, D. 2003. Golden eggs: maternal manipulation of offspring phenotype by egg androgen in birds. Ardeola 50:281-294.

Godfray, H. C. J. 1991. Signalling of need by offspring to their parents. Nature 352:328-330.

1995. Evolutionary theory of parent-offspring conflict. Nature 376:1133-1138.

1999. Parent-offspring conflict. Pages 100-120 in L. Keller, ed. Levels of selection in evolution. Princeton University Press, Princeton, NJ.

Godsave, S. F., R. Lohmann, R. P. M. Vloet, and M. Gahr. 2002. Androgen receptors in the embryonic zebra finch hindbrain suggest a function for maternal androgens in perihatching survival. Journal of Comparative Neurology 453:57-70.

Gottlander, K. 1987. Parental feeding behaviour and sibling competition in pied flycatchers Ficedula hypoleuca. Ornis Scandinavica 18:269-276.

Groothuis, T. G. G., W. Müller, N. Von Engelhardt, C. Carere, and C. M. Eising. 2005. Maternal hormones as a tool to adjust offspring phenotype in avian species. Neuroscience and Biobehavioral Reviews 29:329-352.

Hackl, R., V. Bromundt, J. Daisley, K. Kotrschal, and E. Möstl. 2003. Distribution and origin of steroid hormones in the yolk of Japanese 
quail eggs (Coturnix coturnix japonica). Journal of Comparative Physiology B 173:327-331.

Haig, D. 1993. Genetic conflicts in human pregnancy. Quarterly Review of Biology 68:495-532.

1996. Placental hormones, genomic imprinting, and maternal-fetal communication. Journal of Evolutionary Biology 9: $357-380$.

Hamilton, W. D. 1964. The genetical evolution of social behaviour. Journal of Theoretical Biology 7:1-52.

Hayward, L. S., and J. C. Wingfield. 2004. Maternal corticosterone is transferred to avian yolk and may alter offspring growth and adult phenotype. General and Comparative Endocrinology 135: 365-371.

Hayward, L. S., J. B. Richardson, M. N. Grogan, and J. C. Wingfield. 2006. Sex differences in the organizational effects of corticosterone in the egg yolk of quail. General and Comparative Endocrinology 146:144-148.

Hinde, C. A. 2006. Negotiation over offspring care? a positive response to partner-provisioning rate in great tits. Behavioral Ecology 17:6-12.

Hitchins, M. P., and G. E. Moore. 2002. Genomic imprinting in fetal growth and development. Expert Reviews in Molecular Medicine 9:1-19.

Houston, A. I., T. Székely, and J. M. McNamara. 2005. Conflict between parents over care. Trends in Ecology \& Evolution 20:3338.

Johnstone, R. A. 1996. Begging signals and parent-offspring conflict: do parents win? Proceedings of the Royal Society B: Biological Sciences 263:1677-1681.

Johnstone, R. A., and H. C. J. Godfray. 2002. Models of begging as a signal of need. Pages 1-20 in J. Wright and M. L. Leonard, eds. The evolution of begging, competition, cooperation and communication. Kluwer, Dordrecht.

Ketterson, E. D., V. Nolan Jr., and M. Sandell. 2005. Testosterone in females: mediator of adaptive traits, constraint on sexual dimorphism, or both? American Naturalist 166(suppl.):S85-S98.

Kilner, R. 2002a. The evolution of complex begging displays. Pages 87-106 in J. Wright and M. L. Leonard, eds. The evolution of begging, competition, cooperation and communication. Kluwer, Dordrecht.

- 2002b. Sex differences in canary (Serinus canaria) provisioning rules. Behavioral Ecology and Sociobiology 52:400-407.

Kölliker, M. 2005. Ontogeny in the family. Behavior Genetics 35:718.

Kölliker, M., and H. Richner. 2001. Parent-offspring conflict and the genetics of offspring solicitation and parental response. Animal Behaviour 62:395-407.

Kölliker, M., M. W. G. Brinkhof, P. Heeb, P. S. Fitze, and H. Richner. 2000. The quantitative genetic basis of offspring solicitation and parental response in a passerine bird with biparental care. Proceedings of the Royal Society B: Biological Sciences 267:2127-2132.

Kölliker, M., E. D. Brodie III, and A. J. Moore. 2005. The coadaptation of parental supply and offspring demand. American Naturalist 166:506-516.

Lefebvre, L., S. Viville, S. C. Barton, F. Ishino, E. B. Keverne, and M. A. Surani. 1998. Abnormal maternal behavior and growth retardation associated with loss of the imprinted gene Mest. Nature Genetics 20:163-169.

Lessells, C. M. 1999. Sexual conflict in animals. Pages 75-99 in L.
Keller, ed. Levels of selection in evolution. Princeton University Press, Princeton, NJ.

- 2002. Parentally biased favouritism: why should parents specialize in caring for different offspring? Philosophical Transactions of the Royal Society B: Biological Sciences 357:381-403.

- 2006. The evolutionary outcome of sexual conflict. Philosophical Transactions of the Royal Society B: Biological Sciences 361:301-317.

Lessells, C. M., and G. A. Parker. 1999. Parent-offspring conflict: the full-sib-half-sib fallacy. Proceedings of the Royal Society B: Biological Sciences 266:1637-1643.

Li, L. L., E. B. Keverne, S. A. Aparicio, F. Ishino, S. C. Barton, and M. A. Surani. 1999. Regulation of maternal behavior and offspring growth by paternally expressed Peg3. Science 284:330-333.

Love, O. P., E. H. Chin, K. E. Wynne-Edwards, and T. D. Williams. 2005. Stress hormones: a link between maternal condition and sex-biased reproductive investment. American Naturalist 166:751766.

MacGregor, N. A., and A. Cockburn. 2002. Sex differences in parental response to begging nestlings in superb fairy wrens. Animal Behaviour 63:923-932.

Minivielle, F., B. B. Kayang, M. Inoue-Murayama, M. Miwa, A. Vignal, D. Gourichon, A. Neau, L. Monvoisin, and I. Shin'ichi. 2005. Microsatellite mapping of QTL affecting growth, feed consumption, egg production, tonic immobility and body temperature of Japanese quail. BMC Genomics 6:87.

Mock, D. W., and G. A. Parker. 1997. The evolution of sibling rivalry. Oxford University Press, Oxford.

Mock, D. W., H. Drummond, and C. H. Stinson. 1990. Avian siblicide. American Scientist 78:438-449.

Mock, D. W., P. L. Schwagmeyer, and G. A. Parker. 2005. Male house sparrows deliver more food to experimentally subsidized offspring. Animal Behaviour 70:225-236.

Moore, A. J., and T. Pizzari. 2005. Quantitative genetic models of sexual conflict based on interacting phenotypes. American Naturalist 165(suppl.):S88-S97.

Moore, A. J., J. B. Wolf, and E. D. Brodie III. 1998. The influence of direct and indirect genetic effects on the evolution of behavior: social and sexual selection meet maternal effects. Pages 22-41 in T. A. Mousseau and C. W. Fox, eds. Maternal effects as adaptations. Oxford University Press, Oxford.

Moore, T., and D. Haig. 1991. Genomic imprinting in mammalian development: a parental tug-of-war. Trends in Genetics 7:45-49.

Mousseau, T. A., and C. W. Fox. 1998a. The adaptive significance of maternal effects. Trends in Ecology \& Evolution 13:403-407.

- eds. 1998b. Maternal effects as adaptations. Oxford University Press, New York.

Navara, K. J., L. M. Siefferman, G. E. Hill, and M. T. Mendonça. 2006. Yolk androgens vary inversely to maternal androgens in eastern bluebirds: an experimental study. Functional Ecology 20: 449-456.

Nelson, R. J. 2005. An introduction to behavioral endocrinology. 3rd ed. Sinauer, Sunderland, MA.

Nolan, C. M., J. K. Killian, J. N. Petite, and R. Jirtle. 2001. Imprint status of M6P/IGF2R and IGF2 in chickens. Development Genes and Evolution 211:179-183.

O'Connor, R. J. 1978. Brood reduction in birds: selection for fratricide, infanticide and suicide? Animal Behaviour 26:79-96.

O’Neill, M. J., R. S. Ingram, P. B. Vrana, and S. M. Tilghman. 2000. 
Allelic expression of IGF2 in marsupials and birds. Development Genes and Evolution 210:18-20.

Ottosson, U., J. Bäckman, and H. G. Smith. 1997. Begging affects parental effort in the pied flycatcher, Ficedula hypoleuca. Behavioral Ecology and Sociobiology 41:381-384.

Parker, G. A., N. J. Royle, and I. R. Hartley. 2002. Intrafamilial conflict and parental investment: a synthesis. Philosophical Transactions of the Royal Society B: Biological Sciences 357:295-307.

Pilz, K. M., M. Quiroga, H. Schwabl, and E. Adkins-Regan. 2004. European starling chicks benefit from high yolk testosterone levels during a drought year. Hormones and Behavior 46:179-192.

Price, T. 1998. Maternal and paternal effects in birds: effects on offspring fitness. Pages 202-226 in T. A. Mousseau and C. W. Fox, eds. Maternal effects as adaptations. Oxford University Press, Oxford.

Quillfeldt, P., J. F. Masello, and K. C. Hamer. 2004. Sex differences in provisioning rules and honest signalling of need in Manx shearwaters, Puffinus puffinus. Animal Behaviour 68:613-620.

Rossiter, M. C. 1996. Incidence and consequences of inherited environmental effects. Annual Review of Ecology and Systematics 27:451-476.

Royle, N., I. R. Hartley, I. P. F. Owens, and G. A. Parker. 1999. Sibling competition and the evolution of growth rates in birds. Proceedings of the Royal Society B: Biological Sciences 266:923-932.

Rubolini, D., M. Romano, G. Boncoraglio, R. P. Ferrari, R. Martinelli, P. Galeotti, M. Fasola, and N. Saino. 2005. Effects of elevated egg corticosterone levels on behavior, growth, and immunity of yellowlegged gull (Larus michahellis) chicks. Hormones and Behavior 47: 592-605.

Rutkowska, J., M. Cichon, M. Puerta, and D. Gil. 2005. Negative effects of elevated testosterone on female fecundity in zebra finches. Hormones and Behavior 47:585-591.

Schwabl, H. 1993. Yolk is a source of maternal testosterone for developing birds. Proceedings of the National Academy of Sciences of the USA 90:11446-11450.

. 1996. Maternal testosterone in the egg enhances postnatal growth. Comparative Biochemistry and Physiology A 114:271-276. . 1998. Mother knows best. Natural History 107:24-25.

Schwabl, H., D. W. Mock, and J. A. Gieg. 1997. A hormonal mechanism for parental favouritism. Nature 386:231.

Shahabi, N., J. M. Bahr, and A. V. Nalbandov. 1975. Steroid levels in follicles and the plasma of hens during the ovulatory cycle. Endocrinology 96:962-968.

Slagsvold, T. 1997. Brood division in birds in relation to offspring size: sibling rivalry and parental control. Animal Behaviour 54: $1357-1368$

Slagsvold, T., T. Amundsen, and S. Dale. 1994. Selection by sexual conflict for evenly spaced offspring in blue tits. Nature 370:136138.

- 1995. Costs and benefits of hatching asynchrony in blue tits Parus caeruleus. Journal of Animal Ecology 64:563-578.

Sockman, K. W., and H. Schwabl. 2000. Yolk androgens reduce offspring survival. Proceedings of the Royal Society B: Biological Sciences 267:1451-1456.

Stamps, J., A. Clark, P. Arrowood, and B. Kus. 1985. Parent-offspring conflict in budgerigars. Behaviour 94:1-40.

Stamps, J., A. Clark, B. Kus, and P. Arrowood. 1987. The effects of parent and offspring gender on food allocation in budgerigars. Behaviour 101:177-179.

Tilghman, S. M. 1999. The sins of the fathers and mothers: genomic imprinting in mammalian development. Cell 96:185-193.

Tilly, J. L., and A. L. Johnson. 1989. Regulation of androstenedione production by adenosine $3 \mathrm{~V}, 5 \mathrm{~V}$-monophosphate and phorbol myristate acetate in ovarian thecal cells of the domestic hen. Endocrinology 125:1691-1699.

Trivers, R. L. 1972. Parental investment and sexual selection. Pages 136-179 in B. Campbell, ed. Sexual selection and the descent of man, 1871-1971. Aldine Atherton, Chicago.

\section{4.}

Tuiskula-Haaivisto, M., D. J. De Koning, M. Honkatukia, N. F. Schulman, A. Mäki-Tanila, and J. Vilkki. 2004. Quantitative trait loci with parent-of-origin effects in chicken. Genetical Research 84:5766.

von Engelhardt, N., C. Carere, C. Dijkstra, and T. G. G. Groothuis. 2006. Elevation of yolk testosterone abolishes sex differences in begging and growth of zebra finches. Proceedings of the Royal Society B: Biological Sciences 273:65-70.

Wade, J., A. Gong, and A. P. Arnold. 1997. Effects of embryonic estrogen on differentiation of the gonads and secondary sexual characteristics of male zebra finches. Journal of Experimental Zoology 278:405-411.

Whittingham, L. A., P. O. Dunn, and E. D. Clotfelter. 2003. Parental allocation of food to nestling tree swallows: the influence of nestling behaviour, sex and paternity. Animal Behaviour 65:1203-1210.

Williams, T. D., A. S. Kitaysky, and F. Vézina. 2004. Individual variation in plasma estradiol-17 $\beta$ and androgen levels during egg formation in the European starling Sturnus vulgaris: implications for regulation of yolk steroids. General and Comparative Endocrinology 136:346-352.

Williams, T. D., C. E. Ames, Y. Kiparissis, and K. E. Wynne-Edwards. 2005. Laying-sequence-specific variation in yolk oestrogen levels, and relationship to plasma oestrogen in female zebra finches (Taeniopygia guttata). Proceedings of the Royal Society B: Biological Sciences 272:173-177.

Wilson, C. M., and F. M. A. McNabb. 1997. Maternal thyroid hormones in Japanese quail eggs and their influence on embryonic development. General and Comparative Endocrinology 107:153165.

Winkler, D. W. 1993. Testosterone in egg yolks: an ornithologist's perspective. Proceedings of the National Academy of Sciences of the USA 90:11439-11441.

Wolf, J. B., E. D. Brodie III, and A. J. Moore. 1999. Interacting phenotypes and the evolutionary process. II. Selection resulting from social interactions. American Naturalist 153:254-266.

Woods, J. E., G. W. de Vries, and R. C. Thommes. 1971. Ontogeny of the pituitary-adrenal axis in the chick embryo. General and Comparative Endocrinology 17:407-415.

Wright, J. 1998. Helpers-at-the-nest have the same provisioning rule as parents: experimental evidence from playbacks of chick begging. Behavioral Ecology and Sociobiology 42:423-429.

Associate Editor: Ellen D. Ketterson Editor: Michael C. Whitlock 